\title{
Pretreatment predictors of adjuvant chemoradiation in patients receiving transoral robotic surgery for squamous cell carcinoma of the oropharynx: a case control study
}

\author{
Harry E. Subramanian', Henry S. Park', Andrea Barbieri², Amit Mahajan³, Benjamin L. Judson ${ }^{4}$, Saral Mehra4,
} Wendell G. Yarbrough ${ }^{4}$, Barbara A. Burtness ${ }^{5}$ and Zain A. Husain ${ }^{1 *}$

\begin{abstract}
Background: The purpose of this study was to identify preoperative patient characteristics associated with the incidence of positive surgical margins or lymph node extracapsular extension (ECE), which necessitate adjuvant chemoradiation after transoral robotic surgery (TORS).

Methods: We conducted a single institution retrospective study of 34 consecutive patients with primary oropharyngeal cancer who underwent TORS. All imaging was reviewed by a single neuroradiologist. Surgical margins and ECE status were determined by a single head and neck pathologist. Associations of preoperative patient characteristics with positive surgical margins and lymph node ECE were examined using univariate analysis. Independent predictors of these outcomes were determined using logistic regression.
\end{abstract}

Results: Preoperatively, the majority of patients had early-stage disease (7 CT1 and 21 cT2; 10 cNO). Positive margins occurred in 4 (12\%) patients. A clinically positive lymph node was seen in $23(68 \%)$ patients. Neck dissection was performed in 29 (85\%) patients, among whom 19 had a pathologically positive lymph node and 15 had nodal ECE. Logistic regression showed that larger preoperative lymph node size was an independent predictor of ECE (odds ratio, 13.32 [95 \% Cl, 1.46-121.43]). Among the 21 patients with a clinically positive lymph node who underwent neck dissection, ECE was present more often in patients with a preoperative node size $\geq 3.0 \mathrm{vs.}<3.0 \mathrm{~cm}$ (92\% vs. $44 \%, P=0.046)$. There was no patient characteristic associated with positive margins.

Conclusions: Patients with a larger preoperative lymph node appear more likely to have ECE, and thus be treated with chemoradiation after TORS, with a potentially higher rate of toxicity. Lymph node size should be taken into account when deciding upon treatment approaches. Further research is needed to validate these results.

Keywords: Head and Neck Cancer, Transoral Robotic Surgery, TORS, Oropharyngeal Cancer, Adjuvant Therapy, Extracapsular Extension, Positive Margins

\footnotetext{
* Correspondence: zain.husain@yale.edu

'Department of Therapeutic Radiology, Yale University School of Medicine,

PO Box 208040, New Haven, CT 06510, USA

Full list of author information is available at the end of the article
} 


\section{Background}

Minimally invasive transoral robotic surgery (TORS) has been rapidly adopted across the country for the treatment of oropharyngeal squamous cell carcinoma (OPSCC) [1]. The outcomes following TORS have been encouraging, with less morbidity than conventional surgery $[2,3]$. However, the use of adjuvant therapy after TORS remains high [4]. Based on the landmark studies by the RTOG and EORTC, the addition of cisplatin chemotherapy is indicated in patients with extracapsular extension (ECE) of metastatic lymph nodes or positive surgical margins [5-7]. Although recent analysis has called into question the validity of these guidelines [8], adjuvant chemoradiation remains the standard of care for these high-risk patients, pending further clinical trials. Additionally, positive margins and nodal ECE are indications for dose escalation of radiation therapy [9].

Recent evidence shows nearly $75 \%$ of newly diagnosed OPSCC in the United States are human papillomavirus (HPV) associated, with a more favorable prognosis, and as a result current trials investigate the de-escalation of therapy [10-12]. The potential toxicity advantages of TORS, however, may be negated when patients subsequently receive adjuvant high dose radiation with concurrent chemotherapy. Recent data suggest that trimodality therapy including TORS may result in increased toxicity compared to treatment with definitive chemoradiation [13]. The addition of chemotherapy, escalation of adjuvant radiation dose, and depth of resection have also been associated with an increased incidence of soft tissue necrosis after TORS [14].

Thus it remains important to carefully select patients for TORS. The purpose of this study is to obtain pretreatment predictors for margin positivity and ECE, to help optimize patient selection for TORS.

\section{Methods}

\section{Patients and data collection}

The medical records of all OPSCC patients treated at Yale-New Haven Hospital between January 1, 2010, and November 30, 2014, were retrospectively reviewed. Patients undergoing TORS for a primary OPSCC were extracted. Patients treated for recurrent disease were excluded. This study did not include other surgical modalities such as open surgery, because the incidence of positive margins may vary depending on surgical approach. All cases were discussed at a multi-disciplinary tumor board attended by neuroradiology, pathology, radiation oncology, medical oncology, and otolaryngology. Patients were selected for TORS if there was a consensus at tumor board that there was a high likelihood of achieving negative margins and if the lymph nodes did not demonstrate obvious radiographic evidence of ECE on preoperative examination and imaging.
Information including tumor location, smoking status, p16 status, preoperative tumor size, preoperative lymph node size, neck dissection, surgical margins, ECE, pathologic tumor size, pathologic lymph node size, and receipt of adjuvant therapy were obtained. Preoperative sizes were measured from patient imaging. In order to ensure consistency, all imaging scans were re-reviewed by a single board-certified neuroradiologist, who was blinded to the results of pathologic ECE and margin status. The neuroradiologist identified radiographic ECE based on the presence of irregular borders of the lymph node capsule as well as perinodal fat infiltration. Tumor size was recorded as the largest diameter measured, and lymph node size was recorded as the long-axis diameter of the largest metastatic lymph node in each patient. Surgical margins and the presence of ECE were all re-reviewed for the purposes of this study by a single board-certified head and neck pathologist. In addition, the distance from tumor to the margin was obtained, as well as the extent of ECE, and the ECE grade based on criteria established by Lewis et al. [15]. Surgical margins after TORS were considered positive when tumor cells were present at the resection border.

\section{Statistical analysis}

We analyzed multiple preoperative characteristics of these patients as independent variables to identify possible associations to nodal ECE or positive surgical margins. All analyses were performed using SPSS version 19 (IBM SPSS, Armonk, NY). Chi-square and logistic regression analysis were used to identify predictors of positive margins and ECE. Factors associated with a $P$ value $<0.10$ in univariate analyses were included in multivariable analysis. The study was approved by the Yale University Institutional Review Board, and informed consent was waived.

\section{Results}

Patient characteristics

A total of 34 patients with primary squamous cell carcinoma of the oropharynx undergoing TORS were identified. Overall patient characteristics are summarized in Table 1. The median age was 56.5 years, 28 (82\%) patients had p16-positive tumors, and 21 (62\%) patients were current or former smokers. Preoperatively, the majority of patients had early-stage disease, with seven (21\%) T1 tumors and 21 (62 \%) T2 tumors. A total of 10 (29\%) patients were staged cN0. The overall clinical staging of our patients was distributed as: two (6\%) stage I, six (18\%) stage II, 11 (33\%) stage III, and 14 (42\%) stage IVA. The overall pathologic staging of our patients was distributed as: four (12\%) stage I, five (15\%) stage II, six (18\%) stage III, and 18 (53 \%) stage IVA. In total, eight (24\%) patients were upstaged while three (9\%) patients were downstaged postoperatively. The other 21 (62\%) patients remained the 
Table 1 Patient characteristics $(n=34)$

\begin{tabular}{|c|c|}
\hline Characteristic & Patients \\
\hline Age (Median) & 56.5 \\
\hline \multicolumn{2}{|l|}{ Sex } \\
\hline Male & $25(74 \%)$ \\
\hline Female & $9(27 \%)$ \\
\hline \multicolumn{2}{|l|}{ Location } \\
\hline Tonsil & $17(50 \%)$ \\
\hline Base of Tongue & $16(47 \%)$ \\
\hline Soft Palate & $1(3 \%)$ \\
\hline \multicolumn{2}{|l|}{ Smoking } \\
\hline Smoker & $21(62 \%)$ \\
\hline Non-Smoker & $13(38 \%)$ \\
\hline \multicolumn{2}{|l|}{ p16 } \\
\hline Positive & $28(82 \%)$ \\
\hline Negative & $3(9 \%)$ \\
\hline Undetermined & $3(9 \%)$ \\
\hline Preoperative Tumor Size (median, $n=25$ ) & $2.20 \mathrm{~cm}$ \\
\hline Postoperative Tumor Size (median, $n=31$ ) & $2.20 \mathrm{~cm}$ \\
\hline Preoperative Node Size (median, $n=23$ ) & $3.00 \mathrm{~cm}$ \\
\hline Postoperative Node Size (median, $n=19$ ) & $3.50 \mathrm{~cm}$ \\
\hline \multicolumn{2}{|l|}{ Preoperative T Stage } \\
\hline T0 & $3(9 \%)$ \\
\hline $\mathrm{T} 1$ & $7(21 \%)$ \\
\hline $\mathrm{T} 2$ & $21(62 \%)$ \\
\hline T3 & $2(6 \%)$ \\
\hline T4 & $0(0 \%)$ \\
\hline Unknown & $1(3 \%)$ \\
\hline \multicolumn{2}{|l|}{ Postoperative T Stage } \\
\hline $\mathrm{T} 1$ & $12(35 \%)$ \\
\hline $\mathrm{T} 2$ & $17(50 \%)$ \\
\hline T3 & $4(12 \%)$ \\
\hline $\mathrm{T} 4$ & $0(0 \%)$ \\
\hline Unknown & $1(3 \%)$ \\
\hline \multicolumn{2}{|l|}{ Preoperative N Stage } \\
\hline No & $10(29 \%)$ \\
\hline N1 & $9(27 \%)$ \\
\hline N2 & 14 (41\%) \\
\hline N3 & $0(0 \%)$ \\
\hline Unknown & $1(3 \%)$ \\
\hline \multicolumn{2}{|l|}{ Postoperative N Stage } \\
\hline NO & $13(38 \%)$ \\
\hline N1 & $3(9 \%)$ \\
\hline N2 & $17(50 \%)$ \\
\hline N3 & 1 (3\%) \\
\hline
\end{tabular}

Table 1 Patient characteristics $(n=34)$ (Continued)

\begin{tabular}{|c|c|}
\hline \multicolumn{2}{|l|}{ Preoperative Overall Stage } \\
\hline Stage I & $2(6 \%)$ \\
\hline Stage II & $6(18 \%)$ \\
\hline Stage III & $11(33 \%)$ \\
\hline Stage IVA & $14(42 \%)$ \\
\hline Unknown & $1(3 \%)$ \\
\hline \multicolumn{2}{|l|}{ Postoperative Overall Stage } \\
\hline Stage I & $4(12 \%)$ \\
\hline Stage II & $5(15 \%)$ \\
\hline Stage III & $6(18 \%)$ \\
\hline Stage IVA & $18(53 \%)$ \\
\hline Unknown & $1(3 \%)$ \\
\hline \multicolumn{2}{|l|}{ Lymph Nodes } \\
\hline Positive node on imaging & $23(68 \%)$ \\
\hline Neck dissection performed & $29(85 \%)$ \\
\hline Positive node on dissection & $19(56 \%)$ \\
\hline ECE present & $15(44 \%)$ \\
\hline No ECE present & $14(41 \%)$ \\
\hline Extent of ECE (median, $n=13$ ) & $2.00 \mathrm{~mm}$ \\
\hline \multicolumn{2}{|l|}{ ECE Lewis Grade } \\
\hline 0 & $1(3 \%)$ \\
\hline 1 & $4(12 \%)$ \\
\hline 2 & 7 (21\%) \\
\hline 3 & $7(21 \%)$ \\
\hline 4 & 1 (3\%) \\
\hline \multicolumn{2}{|l|}{ Surgical Margins } \\
\hline Positive & $4(12 \%)$ \\
\hline Negative & $30(88 \%)$ \\
\hline Distance to negative margins (median) & $3.00 \mathrm{~mm}$ \\
\hline \multicolumn{2}{|l|}{ Adjuvant Therapy } \\
\hline None & $10(29 \%)$ \\
\hline Radiation therapy alone & 7 (21\%) \\
\hline Chemoradiation therapy & $17(50 \%)$ \\
\hline
\end{tabular}

ECE indicates extracapsular extension

same stage, and two $(6 \%)$ were not evaluable due to missing staging information. The median time between pretreatment imaging studies and surgery was 29 days. Based on measurements from imaging, the median preoperative tumor size was $2.20 \mathrm{~cm}$, and the median preoperative lymph node size was $3.00 \mathrm{~cm}$.

A positive lymph node was detected on preoperative imaging in $23(68 \%)$ patients. The decision to classify a node as positive was based on review of imaging by a single head and neck radiologist. Neck dissection was performed in $29(85 \%)$ total patients, including 21 (62\%) who had at least one node detected on imaging. 
Nineteen (56 \%) patients had at least one lymph node positive for carcinoma after surgery, and 15 (44\%) had nodal ECE. Only one patient without clinically detected nodes was found to be node positive after surgery, and this patient did not have ECE. Of the 19 (56 \%) patients with at least one positive node after surgery, the median pathologic size was $3.50 \mathrm{~cm}$.

Adjuvant therapy was given to 24 (71\%) patients, with seven $(21 \%)$ receiving radiation therapy alone and 17 (50\%) receiving chemoradiation. This was due to positive margins in one (3\%) patient, ECE in 13 (38\%) patients, and both indications in one (3\%) patient. Two (6\%) patients who had positive nodes detected prior to surgery but did not undergo neck dissection also received adjuvant chemoradiation. Three (9 \%) patients were confirmed as deceased at times of 12, 23, and 36 months after surgery, among whom one (3\%) received no adjuvant therapy, one (3\%) received adjuvant chemoradiation, and one (3\%) received adjuvant radiation, respectively. Further survival analysis was not performed due to the small number of mortality events.

\section{Association between patient characteristics and positive margins}

No patient characteristic was associated with positive margins (Table 2). Evaluated characteristics include smoking history, p16 status, tumor size, and the time interval from pretreatment imaging to surgery. Twentyfive patients $(74 \%)$ were evaluable for the examination of the association between preoperative tumor size and margin positivity. Nine patients were excluded due to a lack of preoperative tumor size due to the primary tumor not being visible on imaging (two patients), a lack of discrete tumor borders on imaging (three patients), or the absence of preoperative imaging prior to excisional biopsy (two patients) or tonsillectomy for presumed tonsillitis (two patients). Positive margins occurred in four patients (12\%). Logistic regression analysis did not show a significant association between preoperative tumor size and positive margins (odds ratio [OR] 1.72 [95\% CI, 0.26-11.45]; $P=0.58)$.

\section{Association between patient characteristics and extracapsular extension}

Association of patient characteristics with extracapsular extension in metastatic lymph nodes was assessed (Table 3). Lymph node size was the only preoperative characteristic associated with nodal ECE. Smoking history, p16 status, and the time interval from preoperative imaging to surgery were not associated with ECE. Twenty one $(62 \%)$ total patients who both had a positive lymph node detected on preoperative imaging and also underwent a neck dissection were evaluable for the examination of the association between preoperative node size and ECE. Patients with a larger preoperative node size were more likely to have ECE (mean $3.23 \mathrm{~cm}$ with ECE vs. $1.88 \mathrm{~cm}$ without ECE, $P<0.01)$. ECE was present more often in patients with a preoperative node size greater than or equal to vs. less than the median size of $3.00 \mathrm{~cm}$ (92\% vs. $44 \%, P=0.046)$. Logistic regression analysis showed that larger preoperative lymph node size was an independent predictor of ECE (OR 13.32 [95\% CI, 1.46-121.43]; $P=0.02$ ).

ECE was identified in nine $(26 \%)$ patients on imaging and in 15 (44\%) patients on pathology. ECE was identified on imaging in eight of the 15 patients with ECE confirmed on pathology (53\% sensitivity). ECE was excluded on imaging in 13 of the 14 patients without ECE on pathology (93\% specificity). In addition the positive and negative predictive values for the use of imaging to predict pathologic ECE were 89 and $65 \%$ respectively.

A sensitivity analysis was performed to determine whether or not these findings would remain robust using different lymph node size thresholds (Table 4). ECE was also present more often in patients with a preoperative node size greater than or equal to vs. less than $2.00 \mathrm{~cm}$ (88 \% vs. $20 \%, P=0.01$ ) and in patients with a preoperative node size greater than or equal to vs. less than $2.50 \mathrm{~cm}(93 \%$ vs. $29 \%, P<0.01)$.

\section{Discussion}

In this series of OPSCC patients undergoing TORS, the rate of margin positivity was $12 \%$ and the rate of nodal ECE was $44 \%$. No clinical features predicted positive margins in this single institution study of predominantly $\mathrm{T} 1$ and T2 cancers, but nodal size emerged as a significant predictor of ECE. No other clinical features were predictive of ECE. These results appear consistent with those reported from a study of the National Cancer Database (NCDB) of patients receiving TORS for oropharyngeal cancer. In that series, the rate of positive margins was $20.2 \%$ in comparison to $12 \%$ in the current study, suggesting our institutional results compare favorably with national practice patterns. The rate of ECE in the NCDB study was $28.5 \%$, although in $17 \%$ of cases the value was unknown making it difficult to compare it to the $44 \%$ who had ECE in the current study. Also, only nodal stage, not largest nodal size was reported in that study, again making direct comparison difficult [1].

It is a key finding of our study that the previously described relationship between nodal size and ECE [16-20] holds even in a largely HPV-associated oropharyngeal carcinoma population. HPV-associated SCC often presents with thin-walled cystic lymph nodes [21]. It is hypothesized that these cystic lymph nodes carry fewer viable tumor cells than a solid lymph node of the same size, raising the question of whether lymph node size would correlate with the risk of ECE in HPV-associated oropharynx 
Table 2 Association between patient characteristics and surgical margins $(n=34)$

\begin{tabular}{|c|c|c|c|}
\hline Characteristic & Positive margins & Negative margins & $P$ Value \\
\hline Age (Mean) & 58.0 & 56.8 & .78 \\
\hline \multicolumn{4}{|l|}{ Sex } \\
\hline Male & $3(12 \%)$ & $22(88 \%)$ & \multirow[t]{2}{*}{$>.99$} \\
\hline Female & $1(11 \%)$ & $8(89 \%)$ & \\
\hline \multicolumn{4}{|l|}{ Location } \\
\hline Tonsil & $1(6 \%)$ & $16(94 \%)$ & \multirow[t]{2}{*}{.34} \\
\hline Base of Tongue & $3(19 \%)$ & $13(81 \%)$ & \\
\hline \multicolumn{4}{|l|}{ Smoking } \\
\hline Smoker & $3(14 \%)$ & $18(86 \%)$ & \multirow[t]{2}{*}{$>.99$} \\
\hline Non-Smoker & $1(8 \%)$ & $12(92 \%)$ & \\
\hline \multicolumn{4}{|l|}{ p16 } \\
\hline Positive & $3(11 \%)$ & $25(89 \%)$ & \multirow[t]{2}{*}{$>.99$} \\
\hline Negative & $0(0 \%)$ & $3(100 \%)$ & \\
\hline Preoperative Tumor Size (Mean) & $2.70 \mathrm{~cm}$ & $2.18 \mathrm{~cm}$ & .59 \\
\hline \multicolumn{4}{|l|}{ Preoperative Tumor Size } \\
\hline Median $=2.20 \mathrm{~cm}$ & & & $>.99$ \\
\hline Less than median size & $0(0 \%)$ & $12(100 \%)$ & \\
\hline Greater than or equal to median size & $1(8 \%)$ & $12(92 \%)$ & \\
\hline Postoperative Tumor Size (Mean) & $3.40 \mathrm{~cm}$ & $2.08 \mathrm{~cm}$ & .03 \\
\hline \multicolumn{4}{|l|}{ Postoperative Tumor Size } \\
\hline Median $=2.20 \mathrm{~cm}$ & & & $>.99$ \\
\hline Less than median size & $1(7 \%)$ & $14(93 \%)$ & \\
\hline Greater than or equal to median size & $2(13 \%)$ & $14(88 \%)$ & \\
\hline Preoperative Node Size (Mean) & $2.85 \mathrm{~cm}$ & $2.89 \mathrm{~cm}$ & .96 \\
\hline \multicolumn{4}{|l|}{ Preoperative Node Size } \\
\hline Median $=3.00 \mathrm{~cm}$ & & & $>.99$ \\
\hline Less than median size & $1(10 \%)$ & $9(90 \%)$ & \\
\hline Greater than or equal to median size & $1(8 \%)$ & $12(92 \%)$ & \\
\hline Postoperative Node Size (Mean) & $3.45 \mathrm{~cm}$ & $3.54 \mathrm{~cm}$ & .93 \\
\hline \multicolumn{4}{|l|}{ Postoperative Node Size } \\
\hline Median $=3.50 \mathrm{~cm}$ & & & $>.99$ \\
\hline Less than median size & $1(13 \%)$ & $7(88 \%)$ & \\
\hline Greater than or equal to median size & $1(9 \%)$ & $10(91 \%)$ & \\
\hline
\end{tabular}

cancer, as it did in reports from two decades ago [16-20], when HPV was much less prevalent and multiple tumor sites were studied. The current study, however, demonstrates that lymph node size remains a strong predictor of ECE even in a largely HPV-associated population. In the current study, lymph nodes $3.0 \mathrm{~cm}$ and larger were associated with a rate of ECE of $92 \%$, which was statistically significantly higher than the $44 \%$ rate of ECE seen in smaller lymph nodes.

In addition to lymph node size, another recently investigated characteristic has been the correlation between radiographic ECE on computed tomography (CT) imaging and pathologic ECE. In our study, the use of radiographic ECE to predict pathologic ECE was associated with a sensitivity, specificity, positive predictive value (PPV), and negative predictive value (NPV) of 53, 93, 89, and $65 \%$, respectively. These findings are fairly consistent with a recent study of 432 patients with oral cavity or laryngeal cancer, which demonstrated a sensitivity, specificity, PPV, and NPV of 43.7, 97.7, 82.6, and $87.3 \%$, respectively, for the use of radiographic ECE to predict pathologic ECE, though our lower NPV may be at least partially attributable to the higher prevalence of pathologic ECE in our study (44\% vs. $20 \%$ ). The authors 
Table 3 Association between patient characteristics and nodal extracapsular extension (ECE) $(n=29)$

\begin{tabular}{|c|c|c|c|}
\hline Characteristic & ECE & No ECE & $P$ Value \\
\hline Age (Mean) & 55.5 & 58.4 & .35 \\
\hline \multicolumn{4}{|l|}{ Sex } \\
\hline Male & $12(55 \%)$ & $10(46 \%)$ & \multirow[t]{2}{*}{.68} \\
\hline Female & $3(43 \%)$ & $4(57 \%)$ & \\
\hline \multicolumn{4}{|l|}{ Location } \\
\hline Tonsil & $8(62 \%)$ & $5(39 \%)$ & \multirow[t]{2}{*}{.48} \\
\hline Base of Tongue & $7(47 \%)$ & $8(53 \%)$ & \\
\hline \multicolumn{4}{|l|}{ Smoking } \\
\hline Smoker & $9(53 \%)$ & $8(47 \%)$ & \multirow[t]{2}{*}{$>.99$} \\
\hline Non-Smoker & $6(50 \%)$ & $6(50 \%)$ & \\
\hline \multicolumn{4}{|l|}{ p16 } \\
\hline Positive & $14(61 \%)$ & $9(39 \%)$ & \multirow[t]{2}{*}{.56} \\
\hline Negative & $1(33 \%)$ & $2(67 \%)$ & \\
\hline Preoperative Tumor Size (Mean) & $2.18 \mathrm{~cm}$ & $2.13 \mathrm{~cm}$ & .86 \\
\hline \multicolumn{4}{|l|}{ Preoperative Tumor Size } \\
\hline \multicolumn{3}{|l|}{ Median $=2.20 \mathrm{~cm}$} & \multirow[t]{3}{*}{$>.99$} \\
\hline Less than median size & $6(55 \%)$ & $5(46 \%)$ & \\
\hline Greater than or equal to median size & $4(50 \%)$ & $4(50 \%)$ & \\
\hline Postoperative Tumor Size (Mean) & $1.90 \mathrm{~cm}$ & $2.26 \mathrm{~cm}$ & .33 \\
\hline \multicolumn{4}{|l|}{ Postoperative Tumor Size } \\
\hline \multicolumn{3}{|l|}{ Median $=2.20 \mathrm{~cm}$} & \multirow[t]{3}{*}{$>.99$} \\
\hline Less than median size & $8(53 \%)$ & 7 (47 \%) & \\
\hline Greater than or equal to median size & $6(50 \%)$ & $6(50 \%)$ & \\
\hline Preoperative Node Size (Mean) & $3.23 \mathrm{~cm}$ & $1.88 \mathrm{~cm}$ & .002 \\
\hline \multicolumn{4}{|l|}{ Preoperative Node Size } \\
\hline \multicolumn{3}{|l|}{ Median $=3.00 \mathrm{~cm}$} & \multirow[t]{3}{*}{.046} \\
\hline Less than median size & $4(44 \%)$ & $5(56 \%)$ & \\
\hline Greater than or equal to median size & $11(92 \%)$ & $1(8 \%)$ & \\
\hline Postoperative Node Size (Mean) & $3.83 \mathrm{~cm}$ & $2.38 \mathrm{~cm}$ & .03 \\
\hline \multicolumn{4}{|l|}{ Postoperative Node Size } \\
\hline \multicolumn{3}{|l|}{ Median $=3.50 \mathrm{~cm}$} & \multirow[t]{3}{*}{.02} \\
\hline Less than median size & $4(50 \%)$ & $4(50 \%)$ & \\
\hline Greater than or equal to median size & $11(100 \%)$ & $0(0 \%)$ & \\
\hline \multicolumn{4}{|l|}{ Number of Positive Nodes on Imaging } \\
\hline 1 & 10 (71 \%) & $4(29 \%)$ & \multirow[t]{2}{*}{$>.99$} \\
\hline 2 or more & $5(71 \%)$ & $2(29 \%)$ & \\
\hline \multicolumn{4}{|l|}{ Number of Positive Nodes on Dissection } \\
\hline 1 & $5(71 \%)$ & $2(29 \%)$ & \multirow[t]{2}{*}{.60} \\
\hline 2 or more & $10(83 \%)$ & $2(17 \%)$ & \\
\hline \multicolumn{4}{|l|}{ ECE on Imaging } \\
\hline Positive & $8(89 \%)$ & $1(11 \%)$ & \multirow[t]{2}{*}{.01} \\
\hline Negative & 7 (35 \%) & 13 (65 \%) & \\
\hline
\end{tabular}

Table 3 Association between patient characteristics and nodal extracapsular extension (ECE) $(n=29)$ (Continued)

\begin{tabular}{llll}
\hline Node Necrosis on Imaging & & & \\
Positive & $12(86 \%)$ & $2(14 \%)$ & .001 \\
Negative & $3(20 \%)$ & $12(80 \%)$ & \\
\hline
\end{tabular}

ECE indicates extracapsular extension

concluded that these values are reasonable for use in clinical decision making [22]. In another study of 100 patients with head and neck cancer, the sensitivity, specificity, PPV, and NPV by two independent radiologists were (1) 49,84 , 84 , and $49 \%$, respectively, and (2) $65,54,71$, and $48 \%$, respectively [23]. The prevalence of pathologic ECE in this study was $63 \%$. The authors of this study concluded that radiographic ECE is not an adequate predictor of pathologic ECE due in part to a poor NPV. The criteria used to identify radiographic ECE in our study and these two studies were irregular borders of the lymph node capsule as well as perinodal fat infiltration. Although neither of these large studies was limited to oropharyngeal cancer patients and there was a variance in the prevalence of pathologic ECE between studies, the differing conclusions demonstrate the contentious nature surrounding the use of radiographic ECE as a predictor for pathologic ECE.

It should also be noted that debate exists about how the extent of ECE affects prognosis. A study of mostly p16positive oropharyngeal carcinoma demonstrated that while the risk of recurrence was significantly higher with grade 4 extracapsular extension (defined as no residual nodal tissue or architecture, "soft tissue metastases"), this did not appear to affect disease-free or overall survival [15]. An unrelated study of larynx and hypopharynx carcinoma demonstrated that macroscopic extracapsular extension, but not microscopic extension, was associated with risk of recurrence and death [24]. Another study of 35 patients with head and neck squamous cell carcinoma of unknown primary demonstrated lower overall and cancer-specific survival in patients with $\geq 2 \mathrm{~mm}$ of ECE [25]. However, a separate study of 266 patients with oral tongue cancer found no difference in survival when comparing patients with $\leq 2 \mathrm{~mm}$ vs. $>2 \mathrm{~mm}$ of ECE [26]. Current clinical trials use $1 \mathrm{~mm}$ of ECE as a cutoff for analysis [27], and further study is needed in this area.

The findings of the current study, if confirmed in larger series, can be used to help guide patient selection for TORS, among patients with T1 and T2 tumors. TORS is a relatively new technique for operative management of oropharyngeal tumors with less morbidity and improved functional outcomes compared to open surgical approaches for similar tumors [28-31]. Nearly $75 \%$ of newly diagnosed oropharyngeal cancers are now associated with HPV and therefore have a more favorable prognosis, leading to current research studies investigating the benefit of 
Table 4 Sensitivity analysis comparing extracapsular extension (ECE) with preoperative node size $(n=21)$

\begin{tabular}{lcll}
\hline Preoperative Node Size & ECE & No ECE & $4(80 \%)$ \\
\hline Less than $2.0 \mathrm{~cm}$ & $1(20 \%)$ & $2(13 \%)$ \\
Greater than or equal to $2.0 \mathrm{~cm}$ & $14(88 \%)$ & $5(71 \%)$ \\
Less than $2.5 \mathrm{~cm}$ & $2(29 \%)$ & $1(7 \%)$ \\
Greater than or equal to $2.5 \mathrm{~cm}$ & $13(93 \%)$ & $5(56 \%)$ \\
Less than $3.0 \mathrm{~cm}$ & $4(44 \%)$ & $1(8 \%)$ \\
Greater than or equal to $3.0 \mathrm{~cm}$ & $11(92 \%)$ & $6(38 \%)$ \\
Less than $3.5 \mathrm{~cm}$ & $10(63 \%)$ & $0(0 \%)$ \\
Greater than or equal to $3.5 \mathrm{~cm}$ & $5(100 \%)$ & $6(32 \%)$ \\
Less than $4.0 \mathrm{~cm}$ & $13(68 \%)$ & $0(0 \%)$ \\
Greater than or equal to $4.0 \mathrm{~cm}$ & $2(100 \%)$ & .26 \\
\hline
\end{tabular}

de-escalation of therapy for these patients [10,11]. Clinical trials currently underway are investigating the effectiveness of reduced-dose adjuvant radiation therapy [27] as well as definitive radiation therapy [32]. In addition, the association between ECE and prognosis in patients with p16-positive oropharyngeal cancer has lately been called into question. Recent retrospective data suggest that ECE is not associated with disease recurrence or survival in these patients [33], and this in turn has cast doubt on the necessity of adjuvant chemoradiation. The question of whether adjuvant chemoradiation is more beneficial than adjuvant radiotherapy alone in patients with ECE in the setting of HPV-related disease is currently being investigated in phase III clinical trials $[34,35]$. However, the results from these studies will not be available for some time. Unfortunately, the patients in the present study were treated prior to de-escalation trials for HPV-associated OPSCC being open at our institution, and so were treated using a standard of care approach.

Limitations of this study include its retrospective design and the small sample size. Another consideration is that the patients in this study underwent TORS during the first four years of robotic surgery at our institution, and greater cumulative case volume may lead to improved outcomes. For instance, national data has shown a lower rate of positive margins in high-volume institutions (defined as having more than 10 TORS cases per year) compared to low-volume institutions [1], suggesting the existence of a "learning curve." That said, the rate of positive margins in our study was favorable to national rates, suggesting that experience was not the critical determinant of margin positivity.

\section{Conclusions}

The preoperative lymph node size is an independent predictor of pathologic nodal extracapsular extension in patients with OPSCC who undergo TORS. Patients with lymph nodes larger than $3 \mathrm{~cm}$ may be more likely to have pathologic extracapsular extension necessitating adjuvant chemoradiation, which could put them at a greater risk of requiring trimodality therapy and its associated toxicity. The likelihood of requiring trimodality therapy should be taken into account along with other factors such as patient preference, surgical risk, predicted functional outcomes, and ability to receive chemotherapy, in order to make an individualized recommendation for primary TORS or definitive chemoradiation. These findings are hypothesis-generating and warrant confirmation in larger, multi-institutional datasets. Future prospective studies are needed to evaluate functional and patient-reported outcomes, and determine the optimal management of these patients.

\section{Additional file}

Additional file 1: Database of TORS patients used for analysis. (XLSX $34 \mathrm{~kb})$

\section{Abbreviations}

ECE, extracapsular extension; HPV, human papillomavirus; NCDB, national cancer database; NPV, negative predictive value; OPSCC, oropharyngeal squamous cell carcinoma; PPV, positive predictive value; TORS, transoral robotic surgery

\section{Funding}

Funding was provided by the Yale University School of Medicine Medical Student Research Fellowship. The funding played no role in the design of the study, in the collection, analysis, and interpretation of data, and in writing the manuscript.

\section{Availability of data and materials}

The dataset supporting the conclusions of this article is included within the article and its Additional file 1.

Authors' contributions

All authors made substantial contributions to conception and design, or acquisition of data, or analysis and interpretation of data; and were involved in drafting the manuscript or revising it critically for important intellectual content. All authors read and approved the final manuscript.

\section{Competing interests}

Dr. Park has received honoraria and travel expenses from Varian Medical Systems, Inc. (past). The other authors declare that they have no competing interests. 


\section{Ethics approval and consent to participate}

This study was approved by the Yale University Institutional Review Board, and informed consent was waived.

\section{Author details}

'Department of Therapeutic Radiology, Yale University School of Medicine, PO Box 208040, New Haven, CT 06510, USA. ²Department of Pathology, Yale University School of Medicine, New Haven, CT, USA. ${ }^{3}$ Department of Diagnostic Radiology, Yale University School of Medicine, New Haven, CT, USA. ${ }^{4}$ Section of Otolaryngology, Department of Surgery, Yale University School of Medicine, New Haven, CT, USA. ${ }^{5}$ Department of Medical Oncology, Yale University School of Medicine, New Haven, CT, USA.

\section{Received: 12 April 2016 Accepted: 23 June 2016}

Published online: 04 July 2016

\section{References}

1. Chen MM, Roman SA, Kraus DH, Sosa JA, Judson BL. Transoral robotic surgery: a population-level analysis. Otolaryngol Head Neck Surg. 2014;150(6):968-75.

2. Moore EJ, Hinni ML. Critical review: transoral laser microsurgery and roboticassisted surgery for oropharynx cancer including human papillomavirusrelated cancer. Int J Radiat Oncol Biol Phys. 2013;85(5):1163-7.

3. Kelly K, Johnson-Obaseki S, Lumingu J, Corsten M. Oncologic, functional and surgical outcomes of primary Transoral Robotic Surgery for early squamous cell cancer of the oropharynx: a systematic review. Oral Oncol. 2014:50(8):696-703.

4. Hutcheson KA, Holsinger FC, Kupferman ME, Lewin JS. Functional outcomes after TORS for oropharyngeal cancer: a systematic review. Eur Arch Otorhinolaryngol. 2015;272(2):463-71.

5. Cooper JS, Pajak TF, Forastiere AA, et al. Postoperative concurrent radiotherapy and chemotherapy for high-risk squamous-cell carcinoma of the head and neck. N Engl J Med. 2004;350(19):1937-44.

6. Bernier J, Domenge C, Ozsahin $\mathrm{M}$, et al. Postoperative irradiation with or without concomitant chemotherapy for locally advanced head and neck cancer. N Engl J Med. 2004;350(19):1945-52.

7. Bernier J, Cooper JS, Pajak TF, et al. Defining risk levels in locally advanced head and neck cancers: a comparative analysis of concurrent postoperative radiation plus chemotherapy trials of the EORTC (\#22931) and RTOG (\# 9501). Head Neck. 2005;27(10):843-50.

8. Sinha P, Piccirillo JF, Kallogjeri D, Spitznagel EL, Haughey BH. The role of postoperative chemoradiation for oropharynx carcinoma: a critical appraisal of the published literature and National Comprehensive Cancer Network guidelines. Cancer. 2015;121(11):1747-54.

9. Quon H, O'Malley Jr BW, Weinstein GS. Postoperative adjuvant therapy after transoral robotic resection for oropharyngeal carcinomas: rationale and current treatment approach. ORL J Otorhinolaryngol Relat Spec. 2011;73(3):121-30.

10. O'Sullivan B, Huang SH, Siu LL, et al. Deintensification candidate subgroups in human papillomavirus-related oropharyngeal cancer according to minimal risk of distant metastasis. J Clin Oncol. 2013;31(5):543-50.

11. Psyrri A, Rampias T, Vermorken JB. The current and future impact of human papillomavirus on treatment of squamous cell carcinoma of the head and neck. Ann Oncol. 2014;25(11):2101-15.

12. Chaturvedi AK, Engels EA, Pfeiffer RM, et al. Human papillomavirus and rising oropharyngeal cancer incidence in the United States. J Clin Oncol. 2011:29(32):4294-301.

13. Wooten CE, Wilson WA, Arnold SM, et al. Functional outcomes with surgical and Non-surgical management of locally advanced oropharyngeal cancer. Int J Radiat Oncol Biol Phys. 2014;90(1):S123.

14. Lukens JN, Lin A, Gamerman V, et al. Late consequential surgical bed soft tissue necrosis in advanced oropharyngeal squamous cell carcinomas treated with transoral robotic surgery and postoperative radiation therapy. Int J Radiat Oncol Biol Phys. 2014;89(5):981-8.

15. Lewis Jr JS, Carpenter DH, Thorstad WL, Zhang Q, Haughey BH. Extracapsular extension is a poor predictor of disease recurrence in surgically treated oropharyngeal squamous cell carcinoma. Mod Pathol. 2011;24(11):1413-20

16. Johnson JT, Barnes EL, Myers EN, Schramm Jr VL, Borochovitz D, Sigler BA. The extracapsular spread of tumors in cervical node metastasis. Arch Otolaryngol. 1981;107(12):725-9.

17. Snow GB, Annyas AA, van Slooten EA, Bartelink H, Hart AA. Prognostic factors of neck node metastasis. Clin Otolaryngol Allied Sci. 1982;7(3):185-92.
18. Snyderman NL, Johnson JT, Schramm Jr VL, Myers EN, Bedetti CD, Thearle P. Extracapsular spread of carcinoma in cervical lymph nodes. Impact upon survival in patients with carcinoma of the supraglottic larynx. Cancer. 1985; 56(7):1597-9.

19. Carter RL, Bliss JM, Soo KC, O'Brien CJ. Radical neck dissections for squamous carcinomas: pathological findings and their clinical implications with particular reference to transcapsular spread. Int J Radiat Oncol Biol Phys. 1987;13(6):825-32.

20. Hirabayashi H, Koshii K, Uno K, et al. Extracapsular spread of squamous cell carcinoma in neck lymph nodes: prognostic factor of laryngeal cancer. Laryngoscope. 1991;101(5):502-6.

21. Koch WM. Clinical features of HPV-related head and neck squamous cell carcinoma: presentation and work-up. Otolaryngol Clin North Am. 2012; 45(4):779-93.

22. Prabhu RS, Magliocca KR, Hanasoge $S$, et al. Accuracy of computed tomography for predicting pathologic nodal extracapsular extension in patients with head-and-neck cancer undergoing initial surgical resection. Int J Radiat Oncol Biol Phys. 2014;88(1):122-9.

23. Chai RL, Rath TJ, Johnson JT, et al. Accuracy of computed tomography in the prediction of extracapsular spread of lymph node metastases in squamous cell carcinoma of the head and neck. JAMA Otolaryngol Head Neck Surg. 2013;139(11):1187-94.

24. Brasilino de Carvalho M. Quantitative analysis of the extent of extracapsular invasion and its prognostic significance: a prospective study of 170 cases of carcinoma of the larynx and hypopharynx. Head Neck. 1998;20(1):16-21.

25. Keller LM, Galloway TJ, Holdbrook T, et al. p16 status, pathologic and clinical characteristics, biomolecular signature, and long-term outcomes in head and neck squamous cell carcinomas of unknown primary. Head Neck. 2014; 36(12):1677-84.

26. Greenberg JS, Fowler R, Gomez J, et al. Extent of extracapsular spread: a critical prognosticator in oral tongue cancer. Cancer. 2003;97(6):1464-70.

27. Eastern Cooperative Oncology Group; National Cancer Institute. Transoral surgery followed by low-dose or standard-dose radiation therapy with or without chemotherapy in treating patients with HPV positive stage III-IVA oropharyngeal cancer. In: ClinicalTrials.gov [Internet]. Bethesda: National Library of Medicine (US). 2013 [cited 2015 Dec 20]. Available from: https:// clinicaltrials.gov/ct2/show/NCT01898494.

28. Weinstein GS, O'Malley Jr BW, Desai SC, Quon H. Transoral robotic surgery: does the ends justify the means? Curr Opin Otolaryngol Head Neck Surg. 2009;17(2):126-31

29. Moore EJ, Olsen KD, Kasperbauer JL. Transoral robotic surgery for oropharyngeal squamous cell carcinoma: a prospective study of feasibility and functional outcomes. Laryngoscope. 2009;119(11):2156-64.

30. Moore EJ, Olsen SM, Laborde RR, et al. Long-term functional and oncologic results of transoral robotic surgery for oropharyngeal squamous cell carcinoma. Mayo Clin Proc. 2012;87(3):219-25.

31. Weinstein GS, O'Malley Jr BW, Snyder W, Sherman E, Quon H. Transoral robotic surgery: radical tonsillectomy. Arch Otolaryngol Head Neck Surg. 2007;133(12):1220-6

32. NRG Oncology; National Cancer Institute. Reduced-dose intensitymodulated radiation therapy with or without cisplatin in treating patients with advanced oropharyngeal cancer. In: ClinicalTrials.gov [Internet]. Bethesda: National Library of Medicine (US). 2014 [cited 2016 May 20]. Available from: https://clinicaltrials.gov/ct2/show/NCT02254278.

33. Sinha P, Kallogjeri D, Gay H, et al. High metastatic node number, not extracapsular spread or $\mathrm{N}$-classification is a node-related prognosticator in transorally-resected, neck-dissected p16-positive oropharynx cancer. Ora Oncol. 2015;51(5):514-20.

34. Washington University School of Medicine. Post Operative Adjuvant Therapy De-intensification Trial for Human Papillomavirus-related, p16+ Oropharynx Cancer (ADEPT). In: ClinicalTrials.gov [Internet]. Bethesda: National Library of Medicine (US). 2012 [cited 2015 Aug 20]. Available from: https://clinicaltrials.gov/ct2/show/NCT01687413.

35. Owadally W, Hurt C, Timmins $H$, et al. PATHOS: a phase II/III trial of riskstratified, reduced intensity adjuvant treatment in patients undergoing transoral surgery for Human papillomavirus (HPV) positive oropharyngeal cancer. BMC Cancer. 2015;15:602. 